\title{
Antimicrobial resistance surveillance among gram-negative bacterial isolates from patients in hospitals in Khartoum
} State, Sudan [version 1; peer review: 3 approved with reservations]

\author{
Hana Salaheldin Elbadawi (iD1,2, Kamal Mustafa Elhag1,3, Elsheikh Mahgoub4, \\ Hisham N. Altayb5, Muzamil Mahdi Abdel Hamid (iD)2 \\ ${ }^{1}$ Soba University Hospital, University of Khartoum, Khartoum, Sudan \\ 2Institute of Endemic Diseases, University of Khartoum, Khartoum, Sudan \\ ${ }^{3}$ Ahfad University for Women, Omdurman, Sudan \\ ${ }^{4}$ Department of Microbiology, Faculty of Medicine,, University of Khartoum, Khartoum, Sudan \\ ${ }^{5}$ Department of Microbiology, Faculty of Medical Laboratory Sciences, Sudan for Sciences and Technology, Khartoum, Sudan
}

V1 First published: 05 Feb 2019, 8:156

https://doi.org/10.12688/f1000research.17744.1

Latest published: 05 Feb 2019, 8:156

https://doi.org/10.12688/f1000research.17744.1

\section{Abstract}

Background: Antimicrobial resistance (AMR) among gram-negative bacilli is a global health problem. Surveillance of AMR is required to advise on empirical antimicrobial therapy. This study aimed at evaluating the frequency and the AMR patterns of gram-negative isolates from patients treated in eight hospitals in Khartoum State, Sudan.

Methods: A cross-sectional laboratory-based study was conducted over a 6 months period at the Microbiology Department, Soba University Hospital- Khartoum State, Sudan. All gram-negative isolates from blood, urine, wound, and sputum during the period of study were included. Identification and antimicrobial susceptibility testing were carried out for all isolates.

Results: A total of 734 Gram-negative bacilli were isolated. Klebsiella pneumoniae (249 isolates, 34\%) was the most frequently encountered one, followed by Pseudomonas aeruginosa (153 isolates, $21 \%)$, E.coli (123 isolates, 17\%), Acinetobacter baumannii (75 isolates, 10\%), Burkholderia cepacia (42 isolates, 6\%), Proteus mirabilis and Proteus vulgaris (28 isolates, each, (4\%) Enterobacter colecaes (28 isolates, $4 \%$ ), Stenotrophomonas maltophilia (21 isolates, $2.8 \%$ ), and other gramnegative bacilli (15 isolates, 2.2\%) The analysis of the antimicrobial susceptibility patterns showed that $134(22.3 \%)$ isolates were resistant to three or more classes of antibiotics, including cephalosporins, $\beta$ lactam- $\beta$-lactamase inhibitor, quinolones, aminoglycosides and carbapenems.

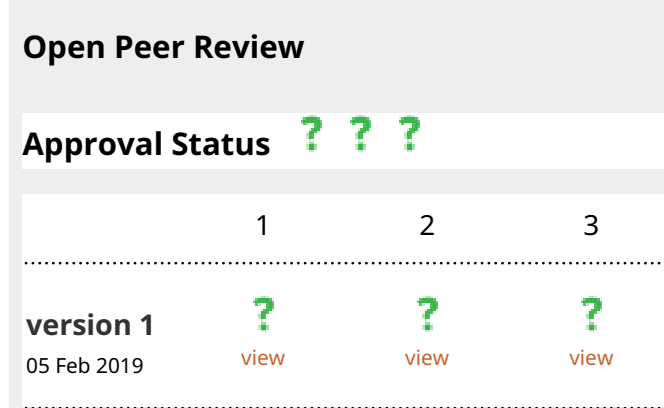

1. Robby Markwart, Robert Koch Institute, Jena University Hospital, Nordufer, Germany Institute of General Practice and Family Medicine, Jena, Germany

2. Rayane Rafei ID, Lebanese University, Tripoli, Lebanon

3. Roberto G Melano, University of Toronto, Toronto, Canada

Any reports and responses or comments on the article can be found at the end of the article. 
Conclusion: This high level of resistance among gram-negative bacilli in Khartoum state hospitals is alarming. The local health authorities should be prompted to step up infection control programs and introduce the concept of antimicrobial stewardship in Khartoum State hospitals.

\section{Keywords}

Gram-negative bacilli, Multidrug resistant bacteria, laboratory-based study, Surveillance.

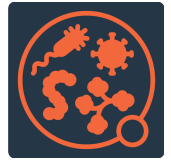

This article is included in the Pathogens

gateway.

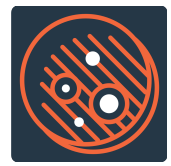

This article is included in the Antimicrobial

Resistance collection.

\section{Corresponding author: Hana Salaheldin Elbadawi (hanasalah200@gmail.com)}

Author roles: Elbadawi HS: Data Curation, Formal Analysis, Methodology, Writing - Original Draft Preparation, Writing - Review \& Editing; Elhag KM: Investigation, Methodology, Writing - Review \& Editing; Mahgoub E: Conceptualization, Methodology, Writing Review \& Editing; Altayb HN: Formal Analysis, Visualization, Writing - Review \& Editing; Abdel Hamid MM: Conceptualization, Supervision, Writing - Review \& Editing

Competing interests: No competing interests were disclosed.

Grant information: This research received partial research fund from the Ministry of Higher Education and Scientific Research, Sudan (grant number SUD/MOH/MMAH/08/2016).

The funders had no role in study design, data collection and analysis, decision to publish, or preparation of the manuscript.

Copyright: @ 2019 Elbadawi HS et al. This is an open access article distributed under the terms of the Creative Commons Attribution License, which permits unrestricted use, distribution, and reproduction in any medium, provided the original work is properly cited.

How to cite this article: Elbadawi HS, Elhag KM, Mahgoub E et al. Antimicrobial resistance surveillance among gram-negative bacterial isolates from patients in hospitals in Khartoum State, Sudan [version 1; peer review: 3 approved with reservations] F1000Research 2019, 8:156 https://doi.org/10.12688/f1000research.17744.1

First published: 05 Feb 2019, 8:156 https://doi.org/10.12688/f1000research.17744.1 


\section{Introduction}

Antimicrobial resistance (AMR) constitutes a continuously growing threat to the effective treatment of microbial infections ${ }^{1}$. However, the direct impact of AMR on the health of hospitalized patients or the people in the community, as well as the financial burden experienced by health care systems in managing the infections and complications due to AMR, are still mostly uncertain ${ }^{2}$. Antibacterial drugs are widely used worldwide both in human health and food industry. Overuse of these medications can favor the selection and the spread of multidrug resistant (MDR) bacteria $^{1}$. Multi drug resistance is defined as resistance to at least three different antibiotic groups, as reported by Masgala and Kostaki ${ }^{3}$. Antibiotic resistance among a variety of bacterial species is increasing in healthcare and community setting. Extended-spectrum $\beta$-lactamase and carbapenemase production are the most frequently emerging resistance mechanisms among gram-negative bacilli ${ }^{4}$. Gram-negative bacilli including Enterobacteriaceae and non-lactose fermenting bacteria such as Pseudomonas spp. and Acinetobacter spp. are the main causes of hospital-acquired infection in critical care units ${ }^{2,5}$. The antibiotic resistance rates among these organisms have amplified uncontrollably in a matter of a few years to become worldwide ${ }^{2}$. According to the Centre for Disease Control and Prevention, gram-negative bacilli are able to develop antibiotic resistance through multiple methods and are particularly competent at spreading the resistance among species via horizontal gene transfer ${ }^{6}$. The enigma of AMR is particularly plaguing low- and middle-income countries, where infectious diseases are the commonest cause of hospitalization and death; and the newer antibiotics cannot be afforded ${ }^{7}$.

AMR surveillance is key for determining the prevalence patterns of AMR, which is fundamental for the development of national and international treatment strategies. Most of the available surveillance data are derived from developed countries; the studies conducted in developing countries are unfortunately not adequate.

This surveillance study was undertaken in order to find out the different types of the AMR patterns of bacterial pathogens isolated from patients in Khartoum State, Sudan. This study may help in formulating antibiotic policies tailored to our hospitals. These data can be used as "information for action" antibiotic stewardship and interventions to optimize antibiotic prescribing practice, therefore prolongs the usefulness of existing antibiotics.

\section{Methods}

Study design and clinical strains

This is a cross-sectional laboratory based study carried out in the department of medical microbiology Soba University Hospital (SUH) and Institute of Endemic Diseases, University of Khartoum, Sudan. A total of 734 Gram-negative bacteria were isolated from patients treated in eight hospitals in Khartoum state including: two university hospitals (Soba university hospital and Bashaier); three teaching hospitals (Ibrahim Malik, Bahri and Sadabulalla), a specialized hospital (Elfouad), and two private hospitals (Imperial and Elswedy). This study included all clinical specimens received in Soba University hospital microbiology laboratory in a period from October 2016 to February 2017 from various wards in the aforementioned hospitals including: intensive care units (ICUs), neonatal ICUs, medicine units, surgery units, pediatric units, and renal units. The isolates were collected from different clinical specimens including: blood (243 isolates, $33.1 \%$ ), urine (230 isolates, $31.3 \%$ ), wounds (183 isolates, $25 \%$ ), sputum (22 isolates, 3\%), catheter tips (26 isolates, $3.4 \%$ ) and body fluids (including cerebrospinal, peritoneal, pleural, acetic and synovial fluid; 30 isolates $4.2 \%$ ). Microorganisms were grown on Blood, Chocolate and MacConkey agar. Then, they were identified according to standard microbiological procedures (based on colony morphology, microscopy, and biochemical tests $)^{8}$. Quality control strains were used in biochemical tests and antimicrobial susceptibility testing [E. coli (ATCC \#25922) and P. aeruginosa (ATCC \#27853)].

Most gram-negative Bacilli isolates were further identified and confirmed by PCR. Guanidine chloride method, as described by Alsadig et al. ${ }^{9}$, was used for DNA extraction followed by PCR which it was carried out using thermal cycler (analytikjena ${ }^{\circledR}$ Biometra TADVANCED, Germany), by using the following primers (Macrogen, Korea), using species-specific primers for Klebsiella pneumoniae, Escherichia coli, Pseudomonas aeruginosa, Acinetobacter baumannii and Universal 16S rRNA primers (Table 1) the reaction was carried out in a total reaction volume of $25 \mu \mathrm{l}(5 \mu \mathrm{l}$ Master mix of Maxime RT premix kit (iNtRON Biotechnology, Seongnam, Korea), $0.6 \mu \mathrm{l}$ of forward primer, $0.6 \mu \mathrm{l}$ of reverse primer, $2 \mu \mathrm{l}$ of DNA and $16.8 \mu \mathrm{l}$ deionized sterile water). The cycle condition as the following: initial denaturation step at $94^{\circ} \mathrm{C}$ for 5-min, followed by 30 cycles of denaturation at $94^{\circ} \mathrm{C}$ for 45 seconds, primer annealing temperature according to the primers Table 1 for 45 seconds, followed by step of elongation at $72^{\circ} \mathrm{C}$ for 60 seconds and the final elongation at $72^{\circ} \mathrm{C}$ for $5 \min ^{10}$. The purity and integrity of each PCR product was evaluated electrophoresis in a $2 \%$ agarose gel in TBE $1 \mathrm{X}$, that contain $2.5 \mu \mathrm{l}$ of $(20 \mathrm{mg} / \mathrm{ml})$ ethidium bromide at $100 \mathrm{~V}$ for $40 \mathrm{~min}$. The specific amplified product were detected by comparing with 100 base-pairs standard DNA ladder (iNtRON BIOTECHNOLOGY, Seongnam, Korea) Bands were visualized under U.V transilluminater (analytikjena ${ }^{\circledR}$ Biometra BDAcompact, Germany). The PCR product of 16SrRNA were purified and Sanger sequencing was performed by Macrogen Company (Seoul, Korea). Then nucleotides sequences of the genes 16SrRNA achieved were searched for sequence similarity using nucleotide BLAST for species identification ${ }^{11}$.

\section{Antimicrobial susceptibility testing}

Susceptibility testing was performed using the Kirby-Bauer disc-diffusion method; each isolate was swabbed on the MullerHinton agar and the antibiotic discs were placed on top and incubated at $37^{\circ} \mathrm{C}$ for $18-24$ hours ${ }^{12}$. all isolates were tested against the following antibiotic disc (Mast Diagnostic): amoxycillin clavulanate (AMC) $(30 \mu \mathrm{g})$, cefuroxime (CXM) $(30 \mu \mathrm{g})$, cephalexin (CL) $(30 \mu \mathrm{g})$, ceftriaxone (CRO) $(30 \mu \mathrm{g})$, ceftazidime (CAZ) $(30 \mu \mathrm{g})$, meropenem (MEM) $(10 \mu \mathrm{g})$, imipenem (IPM) $(10 \mu \mathrm{g})$, amikacin $(\mathrm{AK})(30 \mu \mathrm{g})$, gentamicin $(\mathrm{Gen})(10 \mu \mathrm{g})$, ciprofloxacin (CIP) $(5 \mu \mathrm{g})$, trimethoprim-sulfamethoxazole (SXT) $(25 \mu \mathrm{g})$, temocillin (TEM) $(30 \mu \mathrm{g})$, azteroname (AZT) $(30 \mu \mathrm{g})$ and 
Table 1. Bacterial gene primers used for PCR.

\begin{tabular}{|c|c|c|c|c|}
\hline $\begin{array}{l}\text { Species specific } \\
\text { primers }\end{array}$ & Primer (5' to $\left.3^{\prime}\right)$ & $\operatorname{Tm}\left({ }^{\circ} \mathrm{C}\right)$ & $\begin{array}{l}\text { Band } \\
\text { size (bp) }\end{array}$ & Ref \\
\hline \multirow[t]{2}{*}{ Universal 16S rRNA } & $\mathrm{F}=\mathrm{AGAGTTTGATCCTGGCTCAG}$ & 58 & 890 & 10 \\
\hline & $\mathrm{R}=\mathrm{CTACGGCTACCTTGTTACGA}$ & 58 & & \\
\hline \multirow[t]{3}{*}{ K. pneumoniae } & $\mathrm{Pf}=\mathrm{ATTTGAAGAGGTTGCAAACGAT}$ & 56 & & 13 \\
\hline & Pr1=TTCACTCTGAAGTTTTCTTGTGTTC & 56 & 130 & \\
\hline & Pr2 = CCG AAG ATG TTT CAC TTC TGA TT & 56 & 260 & \\
\hline \multirow[t]{2}{*}{ E.coli } & ECA75F=GGAAGAAGCTTGCTTCTTTGCTGAC & 52 & 544 & 14 \\
\hline & ECR619R=AGCCCGGGGATTTCACATCTGACTTA & 52 & & \\
\hline \multirow[t]{2}{*}{ Pseudomonas spp. } & $\mathrm{F}=\mathrm{GGGGGATCTTCGGACCTCA}$ & 58 & 956 & 15 \\
\hline & $\mathrm{R}=\mathrm{TCCTTAGAGTGCCCACCCG}$ & 58 & & \\
\hline \multirow[t]{2}{*}{ Acinetobacter } & sp4F CACGCCGTAAGAGTGCATTA & 58 & 294 & 16 \\
\hline & sp4R AACGGAGCTTGTCAGGGTTA & 58 & & \\
\hline A. baumannii & 13TU,sp2FGTTCCTGATCCGAAATTCTCG & 58 & 490 & \\
\hline
\end{tabular}

nitrofrantoine (NIT) $(300 \mu \mathrm{g})$. Results were interpreted according to the Clinical Laboratory Standards Institute (CLSI) guidelines ${ }^{12}$.

\section{Classification of MDR gram-negative Bacilli}

MDR has been considered for clinically significant gramnegative Bacilli such as E. coli, K. pneumoniae, $P$. aeruginosa, and $A$. baumannii based on the aforementioned antimicrobial resistance definition. Classes of antibiotics used for MDR-GNB analysis were aminoglycoside (AMG), cephalosporins (CEPH), carbapenems (CARB), and fluroquinolones (FQ) as follows: bacteria that were MDR for four classes of antibiotics (AMG+ $\mathrm{CEPH}+\mathrm{CARB}+\mathrm{FQ}$ ) and bacteria that were MDR for three classes of antibiotics (either $\mathrm{AMG}+\mathrm{CEPH}+\mathrm{FQ}$, $\mathrm{CARB}+\mathrm{CEPH}+\mathrm{FQ}, \mathrm{AMG}+\mathrm{CEPH}+\mathrm{CARB}$, or $\mathrm{AMG}+\mathrm{FQ}+\mathrm{CARB})^{3}$.

Cephalosporin resistance was defined as resistance to ceftriaxone and ceftazidime, except for P. aeruginosa, where only ceftazidime was used. Carbapenem resistance was defined as resistance to both meropenem and imipenem. Aminoglycoside resistance was defined as resistance to both gentamicin and amikacin, Ciprofloxacin resistance was considered an indication to fluoroquinolones resistance.

\section{Ethical consideration}

Formal permission was obtained from the managers of Soba University Hospital and the Institutional Research Ethics Committee of the Institute of Endemic Diseases, University of Khartoum, approved this study under reference number IEND_REC 12/2017. Patient consent was waived by the Research Ethics Committee.

\section{Statistical analysis}

Data were analysed using Microsoft Excel and SPSS version 20.0. Cross-tabulation was used to present the different relations between data, qualitative data were performed using a $\chi^{2}$ test (significance was set at $p \leq 0.05$ ), which was performed to find the differences between bacterial isolates with resistance to at least one class of antibiotics by specimens (blood, urine, wound and other samples) $p$-values were determined for primary and secondary outcomes.

\section{Results}

Bacterial identification

Isolated Gram-negative bacilli showed different strains, including E. coli (123 isolates, 17\%), K. pneumoniae (249 isolates,34\%), P. aeruginosa (153 isolates, 21\%), A. baumannii (75 isolates, $10 \%$ ), Burkholderia cepacia (42 isolates, 6\%), Proteus mirabilis and Proteus vulgaris (28 isolates, 4\%), Enterobacter colecaes (28 isolates, 4\%), Stenotrophomonas maltophilia (21 isolates, $2.8 \%$ ) and other gram-negative bacilli (15 isolates, $2.2 \%$ ).

While isolates were distributed among the different hospital units, most of the pathogenic strains were isolated from neonatal intensive care unit (ICU) (182 isolates, 24.8\%) mainly K. pneumoniae (77 isolate, $42.3 \%$ ) and pediatric units (175 isolates $23.8 \%$ ) the most prevalent strains were $K$. pneumoniae (50 isolate, $29 \%$ ) and $P$. aeruginosa (44 isolates, 25.1), while medicine (147 isolates, 20\%), K. pneumoniae and E.coli (45 isolates $30.6 \%$ ) for both. For the surgery unit (103 isolates, 14\%) renal unit (78 isolates, 10.7\%) and ICU (49 isolates, 6.7\%) mainly K. pneumoniae (19 isolates, 39\%), P. aeruginosa and A. baumannii were (9 isolates, 20.4) for both. Klebsiella pneumoniae was the most isolated organism from all hospital units. The distribution of different gram-negative isolates is shown in Table 2.

With regard to the distribution of the isolates among different clinical specimens, Klebsiella pneumoniae and Pseudomonas aeruginosa were isolated mainly in blood specimens $39 \%$ and $25 \%$ respectively, while $K$. pneumoniae and E.coli were $36 \%$ and $30 \%$ of urine samples. A. baumannii was isolated from $14 \%$ of wound specimens and P. aeruginosa was isolated from $23 \%$ 
Table 2. The incidence of gram-negative Bacilli isolated from patients admitted to different hospital wards in Khartoum State between October 2016 and February 2017.

\begin{tabular}{|c|c|c|c|c|c|c|c|}
\hline \multirow[t]{2}{*}{ Bacteria } & \multicolumn{6}{|c|}{ Hospital ward } & \multirow[t]{2}{*}{ P-value } \\
\hline & $\begin{array}{l}\text { ICU, } \\
\text { n (\%) }\end{array}$ & $\begin{array}{l}\text { NICU, } \\
\text { n (\%) }\end{array}$ & $\begin{array}{l}\text { Medicine, } \\
\text { n (\%) }\end{array}$ & $\begin{array}{l}\text { Surgery, } \\
\text { n (\%) }\end{array}$ & $\begin{array}{l}\text { Renal } \\
\text { unit, } \mathrm{n}(\%)\end{array}$ & $\begin{array}{l}\text { Paediatric, } \\
\text { n (\%) }\end{array}$ & \\
\hline Klebsiella pneumoniae (249) & $19(39)$ & $77(42.3)$ & $45(30.6)$ & $34(33)$ & $24(31)$ & $50(29)$ & $<0.001$ \\
\hline Escherichia coli (123) & $4(8.1)$ & $9(5)$ & $45(30.6)$ & $22(21.3)$ & $16(21)$ & $25(14.2)$ & $<0.001$ \\
\hline Pseudomonas aeruginosa (153) & $10(20.4)$ & $40(21.9)$ & $24(16.3)$ & $17(16.5)$ & $19(24.3)$ & $44(25.1)$ & $<0.001$ \\
\hline Acinetobacter baumannii (75) & $10(20.4)$ & $18(9.9)$ & $9(6.1)$ & $8(8)$ & $7(9)$ & $24(14)$ & $<0.001$ \\
\hline Burkholderia cepacia (42) & $3(6.1)$ & $11(6)$ & $7(4.7)$ & $6(6)$ & $4(5.1)$ & $11(6.3)$ & $<0.001$ \\
\hline Proteus spp. (28) & $1(2)$ & $3(2)$ & $4(2.7)$ & $9(9)$ & $3(4)$ & $8(5)$ & $<0.001$ \\
\hline Enterobacer spp. (28) & $1(2)$ & $10(5.5)$ & $4(3)$ & $3(3)$ & $4(5.1)$ & $6(3.4)$ & $<0.001$ \\
\hline Stenotrophomonas spp. (21) & $1(2)$ & $10(5.5)$ & $3(2)$ & $2(2)$ & $1(1)$ & $4(2)$ & $<0.001$ \\
\hline Other gram-negative Bacilli (15) & $0(0)$ & $4(2.2)$ & $6(4)$ & $2(2)$ & $0(0)$ & $3(2)$ & $<0.001$ \\
\hline Total (734) & $49(6.7)$ & $182(24.8)$ & $147(20)$ & $103(14)$ & $78(10.7)$ & $175(23.8)$ & $<0.001$ \\
\hline
\end{tabular}

*Other Gram-negative bacilli include Citrobacter species, Serratia species, Vebrio vurneficus and Morganella morganii. †Body fluids include cerebrospinal fluid, peritoneal fluid, pleural fluid, acetic fluid and synovial fluid.

of wound specimens. For more details about gram-negative bacilli among different specimen see Table 3 .

\section{Antimicrobial resistance pattern of clinical isolates}

Antibiotic resistance pattern are shown in Figure 1. Out of 734 isolates tested using the disk diffusion method, the highest percentage of resistance, in $97 \%$ and $93.5 \%$ of isolates, were found against ampicillin and cephalexin, respectively, followed by amoxicillin/clavulanic acid( $90 \%)$, cefotaxime $(89.7 \%)$, ceftriaxone $(88.4 \%)$ and ceftazidime $(79.2 \%)$. In addition, co-trimoxazole and nitrofurantoin resistance were detected in $74.4 \%$ and $75.2 \%$ of isolates, respectively. Resistance rates also were high in ciprofloxacin (45.2\%), gentamicin $(52.5 \%)$ and amikacin $(18.3 \%)$. Meropenem and imipenem were the most effective antibiotic tested, with resistance observed in $21.6 \%$ and $16.2 \%$ of isolates, respectively.

The antimicrobial resistance patterns of most commonly isolated organisms are shown in Figure 2. K. pneumoniae resistant pattern as the following (22\%) of them were resistant to meropenem while $(11 \%)$ were resistant to imipenem, ceftazidime $(80.6 \%)$, Gentamicin (52\%), ciprofloxacin (42\%) and amikacin $(16.7 \%)$. With regard to the E. coli antimicrobial resistant pattern, meropenem (9\%), imipenem $(8 \%)$, ceftazidime $(84.2 \%)$, ciprofloxacin (66.4\%), Gentamicin (53.1\%) and amikacin (12.0\%). In Pseudomonas aeruginosa the resistance rate was meropenem $(20 \%)$, imipenem $(22 \%)$ ceftazidime $(81 \%)$ followed by gentamicin $(57.5 \%)$, ciprofloxacin $(22.5 \%)$ and amikacin (9.5\%). The rate of antimicrobial resistant among A. baumannii was as the following; meropenem $(73.7 \%)$, imipenem $(66.7 \%)$, amikacin (63.2\%), gentamicin (79\%) and ciprofloxacin (79\%).

Multidrug resistance patterns among gram negative Bacilli The gram-negative bacilli that were resistant to several antibiotic groups are shown in Table 4. Of 600 GNB isolates, 134
(22.3\%) isolates were MDR. Of those MDR organisms, 48 isolates $(8 \%)$ were resistant to four classes of antimicrobial drugs: A. baumannii (38 isolates, 50.6\%), K. pneumoniae (9 isolates, $3.6 \%$ ), and $E$. coli (1 isolate, $0.8 \%$ ). A further 86 isolates (14.2\%) were resistant to three classes of antimicrobial drugs: A. baumannii (38 isolates, 50.6\%), K. pneumoniae (47 isolates, 18.8\%), P. aeruginosa (21 isolates, $13.7 \%$ ) and E. coli (6 isolate, $4.8 \%)$.

\section{Discussion}

Infection with MDR gram-negative Bacilli is a major problem worldwide, associated with increased patients morbidity and mortality ${ }^{17}$. In Sudan, the increasing number of MDR bacteria is a real clinical challenge ${ }^{18,19}$. This study was undertaken; to identify the different patterns of AMR in bacterial pathogens isolated from patients treated in various wards of hospitals.

In this study, $K$. pneumoniae and $P$. aeruginosa strains were more prevalent in blood specimens while $K$. pneumoniae and E.coli strains were more frequently isolated in urine specimens.

$K$. pneumoniae is a prominent pathogen causing both hospital-acquired and community-associated infections, including bacteremia, wound infection, pneumonia, urinary tract infections and other infections ${ }^{20,21}$. In this study, $K$. pneumoniae was the most commonly isolated organism from the blood specimens mainly in neonatal sepsis in a high rate (39.8\%). Most of these strains resistant to cephalosporins and other class of antibiotics including carbapenem as reported worldwide ${ }^{7,21,22}$.

E. coli is regarded as the commonest pathogen of the urinary tract, causing complicated and uncomplicated urinary tract infections ${ }^{23}$. In this study, the most frequently observed pathogens in urine specimens were E. coli $(30 \%)$ and $K$. pneumoniae $(36 \%)$. This finding is in harmony with the results of several other studies, including: de Francesco et al., who found that E.coli 
Table 3. The frequency of gram-negative bacilli isolated from different clinical samples obtained from patients treated at Khartoum State hospitals between October 2016 and February 2017.

\begin{tabular}{|l|l|l|l|l|l|l|l|}
\hline & \multicolumn{9}{c}{ Bacteria } & \multicolumn{3}{c}{ Specimen } & & P-value \\
\hline & $\begin{array}{l}\text { Blood, } \\
\mathbf{n}(\%)\end{array}$ & $\begin{array}{l}\text { Urine, } \\
\mathbf{n}(\%)\end{array}$ & $\begin{array}{l}\text { Wounds, } \\
\mathbf{n}(\%)\end{array}$ & $\begin{array}{l}\text { Sputum, } \\
\mathbf{n}(\%)\end{array}$ & $\begin{array}{l}\text { Catheter } \\
\text { tips, } \mathbf{n}(\%)\end{array}$ & $\begin{array}{l}\text { Bodily } \\
\text { fluidst, } \mathbf{n}(\%)\end{array}$ \\
\hline Klebsiella pneumoniae (249) & $94(39)$ & $82(36)$ & $50(27)$ & $7(32)$ & $7(28)$ & $9(29)$ & $<0.001$ \\
\hline Escherichia coli (123) & $15(6.1)$ & $70(30)$ & $31(17)$ & $2(9)$ & $1(4)$ & $4(12.9)$ & $<0.001$ \\
\hline Pseudomonas aeruginosa (153) & $60(25)$ & $32(14)$ & $42(23)$ & $6(27.2)$ & $7(28)$ & $6(25)$ & $<0.001$ \\
\hline Acinetobacter baumannii (75) & $18(7.4)$ & $13(5.6)$ & $25(14)$ & $6(27.2)$ & $7(28)$ & $6(25)$ & $<0.001$ \\
\hline Burkholderia cepacia (42) & $20(8)$ & $9(4)$ & $9(5)$ & $1(5)$ & $1(4)$ & $2(6.4)$ & $<0.001$ \\
\hline Proteus spp. (28) & $6(2.5)$ & $7(3)$ & $12(6.5)$ & $0(0)$ & $2(8)$ & $1(3.2)$ & $<0.001$ \\
\hline Enterobacer spp. (28) & $13(5)$ & $8(3.5)$ & $7(4)$ & $0(0)$ & $0(0)$ & $0(0)$ & $<0.001$ \\
\hline Stenotrophomonas spp. (21) & $12(5)$ & $2(0.9)$ & $5(3)$ & $0(0)$ & $0(0)$ & $2(6.4)$ & $<0.001$ \\
\hline Other gram-negative Bacilli* (15) & $5(2)$ & $7(3)$ & $2(1)$ & $0(0)$ & $1(0)$ & $0(0)$ & $<0.001$ \\
\hline Total (734) & $243(33.1)$ & $230(31.3)$ & $183(25)$ & $22(3)$ & $26(3.4)$ & $30(4.2)$ & $<0.001$ \\
\hline
\end{tabular}

*Other Gram-negative bacilli include Citrobacter species, Serratia species, Vebrio vurneficus and Morganella morganii.

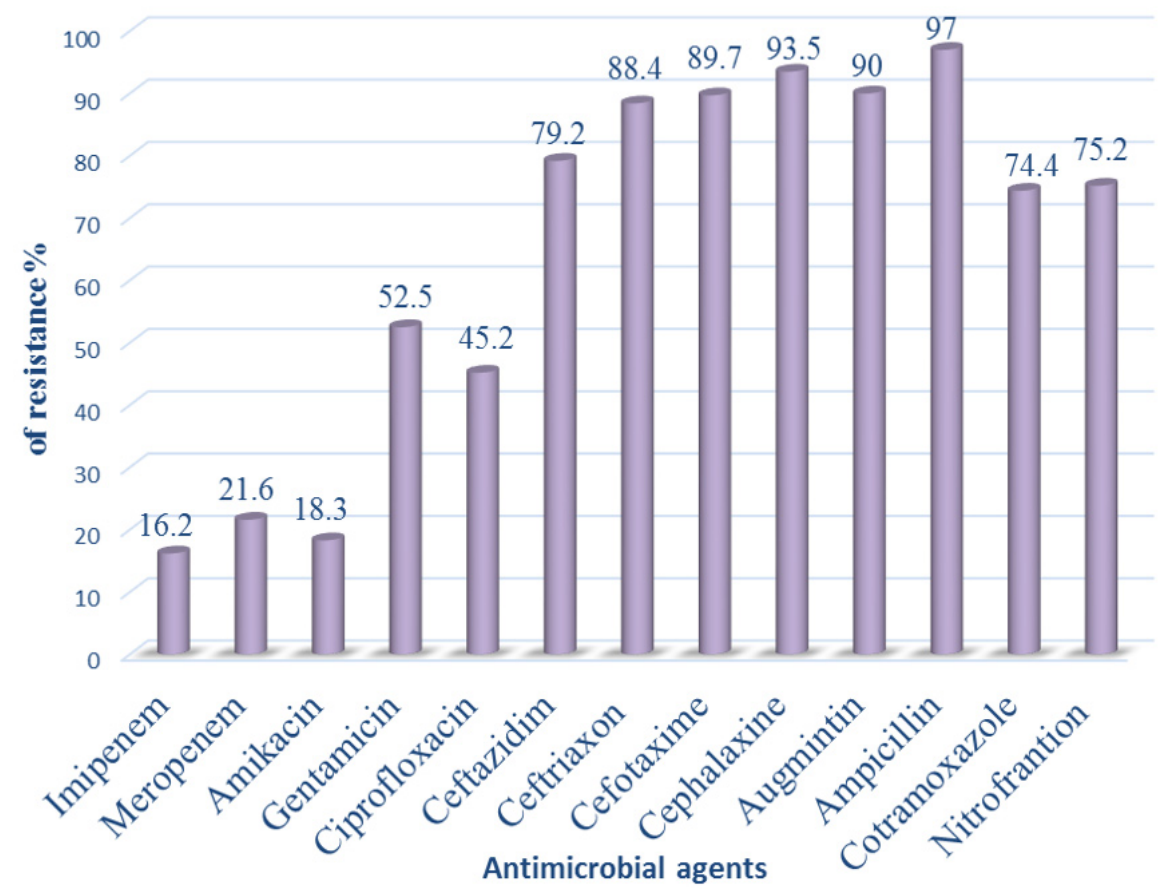

Figure 1. Antimicrobial resistance pattern among different gram-negative Bacilli isolated from patients treated at Khartoum State hospitals between October 2016 and February 2017.

was the commonest GNB (42.4\%) isolate from urine specimens of patients with urinary tract infection ${ }^{24}$; a study in Tanzania reported $38 \%$ of E.coli isolated from urinary specimens ${ }^{25}$ and other studies from Pakistan and India ${ }^{25,26}$.

In this study, non-lactose-fermenting gram-negative bacilli such as $P$. aeruginosa and $A$. baumannii were mostly encountered in ICU patients, these organisms were isolated in $20.4 \%$ of samples, and were found in different clinical samples such as: blood, wound and sputum. This finding agrees with a study by Vincent et al. that reported $P$. aeruginosa and A. baumannii were frequently isolated from ICU patients by Vincent et al. ${ }^{27}$; Jitendra et al., reported that A. baumannii was the second most common pathogen in an ICU of a tertiary care center ${ }^{28}$. 


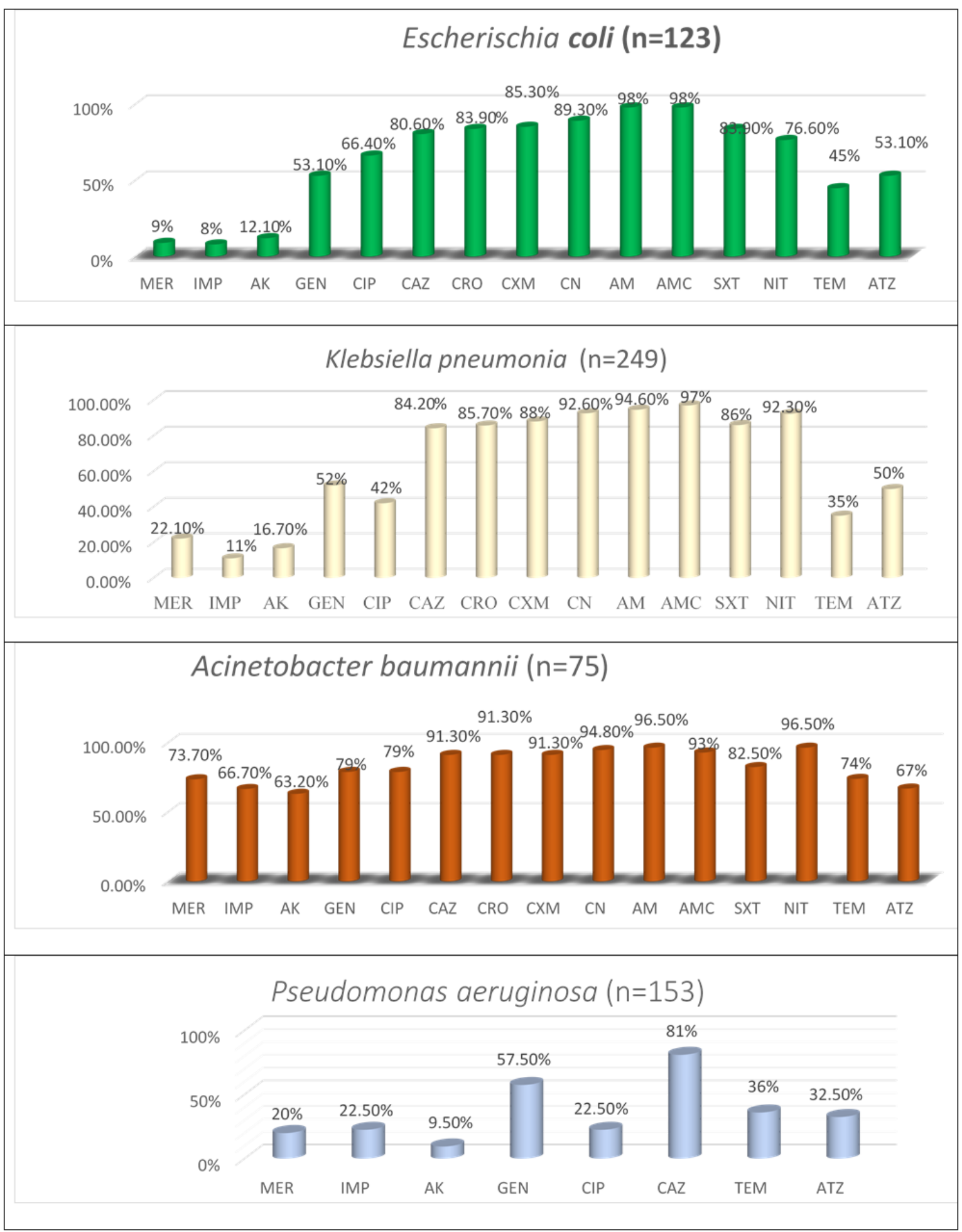

Figure 2. Antimicrobial resistance pattern of commonly isolated organisms' different antibiotics between October 2016 and February 2017. MER, meropenem; IMP, imipenem; AK, amikacin; GEN, gentamicin; CIP, ciprofloxacin; CAZ, ceftazidime; CRO, ceftriaxone; CXM, cefuroxime; CN, cephalexin; AM, ampicillin; AMC, amoxycillin-clavulanate; SXT, trimethoprim-sulfamethoxazole; NIT, nitrofurantoin; TEM, temocillin; ATZ, azetronam. 
Table 4. Multidrug resistance among gram-negative isolates.

\begin{tabular}{|c|c|c|c|c|c|c|}
\hline Class & Resistance to & $\begin{array}{l}\text { Klebsiella } \\
\text { pneumoniae, } \\
\mathrm{n}(\%)\end{array}$ & $\begin{array}{l}\text { Escherichia } \\
\text { coli, n (\%) }\end{array}$ & $\begin{array}{l}\text { Pseudomonas } \\
\text { aeruginosa, } \mathrm{n}(\%)\end{array}$ & $\begin{array}{l}\text { Acinetobacter } \\
\text { baumannii, n (\%) }\end{array}$ & Total, n (\%) \\
\hline $\begin{array}{l}\text { All } \\
\text { isolates }\end{array}$ & NA & 249 & 123 & 153 & 75 & 600 \\
\hline $4 \mathrm{MDR}$ & $\mathrm{AMG}+\mathrm{CEPH}+\mathrm{FQ}+\mathrm{CARB}$ & $9(3.6 \%)$ & $1(0.8 \%)$ & $0(0 \%)$ & $38(50.6 \%)$ & $48(8 \%)$ \\
\hline 3MDR & $\mathrm{AMG}+\mathrm{CEPH}+\mathrm{FQ}$ & $31(12.4 \%)$ & $5(4 \%)$ & $4(2.6 \%)$ & $2(2.6 \%)$ & $42(7 \%)$ \\
\hline 3MDR & $\mathrm{CARB}+\mathrm{CEPH}+\mathrm{FQ}$ & $6(2.4 \%)$ & $0(0 \%)$ & $8(5.2 \%)$ & $8(10.6 \%)$ & $22(3.6 \%)$ \\
\hline 3MDR & $\mathrm{AMG}+\mathrm{CEPH}+\mathrm{CARB}$ & $2(0.8 \%)$ & $0(0 \%)$ & $5(3.2 \%)$ & $1(1.3 \%)$ & $8(1.3 \%)$ \\
\hline 3MDR & $A M G+F Q+C A R B$ & $8(3.2 \%)$ & $1(0.8 \%)$ & $4(2.6 \%)$ & $1(1.3 \%)$ & $22(3.6 \%)$ \\
\hline Total & & $56(22.4 \%)$ & $7(5.6 \%)$ & $21(13.7 \%)$ & $50(66.6 \%)$ & $14(2.3 \%)$ \\
\hline
\end{tabular}

NA, not applicable; AMG, aminoglycoside; CEPH, cephalosporins; FQ, florquinolones; CARB, carbapenem.

Concerning the infection type, we found that $P$. aeruginosa were associated with $25 \%$ of blood stream infections and $23 \%$ of wound infection, while A. baumannii mainly associated with wound infection in $14 \%$ in agree with Gales et al. $2010^{29}$.

Resistance of gram-negative bacilli is widespread and multidrug resistance has been reported in many studies ${ }^{2,4,5}$, causing challenges in the treatment of nosocomial infections. The resistance pattern was commonly reported in classes such as cephalosporins, carbapenem, aminoglycosides and quinolones ${ }^{30-32}$. In this study, we observed high rates of resistance to extended-spectrum $\beta$-lactamases (ESBL), resistance to cephalexin, cefuroxime, ceftazidime and ceftriaxone, in addition to resistance to ampicillin and amoxicillin/clavulanic acid.

The analysis of the antimicrobial susceptibility patterns of the study isolates showed high rate of MDR organisms that were resistant to three or more classes of antibiotics, including carbapenem and aminoglycosides. This pattern was observed mainly among Acinetobacter baumannii, Pseudomonas aeruginosa and Klebsiella pneumoniae.

The most resistant strain was Acinetobacter baumannii, being resistant to all four classes of antibiotics used in $50.6 \%$ of isolates. A total of $73.7 \%$ of $A$. baumannii were found to be resistant to meropenem, and $66.7 \%$ to imipenem, while in the cephalosporin class, more than $91 \%$ of the isolates were resistant. A. baumannii also have high resistance rate to aminoglycosides and quinolones $(63.2 \%$ for amikacin and $79 \%$ for both gentamicin and ciprofloxacin). This increasing resistance among A. baumannii has become a public-health issue, because this bacterium frequently causes nosocomial infections ${ }^{31}$.

In this study the most common clinical isolates of the Enterobacteriaceae family were $K$. pneumonia and E. coli. In both species, there was a high prevalence of resistance against quinolones, aminoglycosides and beta-lactams. Rates of resistance to carbapenems were alarmingly high: $22 \%$ in K. pneumoniae and $9 \%$ in $E$. coli. These bacteria have high resistance rate to ceftazidime and cephalexin, (80.6\% and 92\%, respectively). These rates are much higher than those observed in 2013 by Ali in Soba University hospital, who found that ceftriaxone and ceftazidime resistance rates ranged from $56 \%$ to $79 \%{ }^{21,33}$. Aminoglycoside (specifically amikacin) resistance rates among $K$. pneumoniae and E. coli were $16.7 \%$ and $12.1 \%$, respectively, which is higher than those observed by Lee in 2013, who found the resistance rate to amikacin was $6.2 \%$ in $K$. pneumoniae and $1.3 \%$ in E. coli $^{30}$. In this study Gentamicin resistance among both $K$. pneumoniae and E. coli was $53 \%$, which is a high resistance rate. E. coli was highly resistant to quinolones like ciprofloxacin (in $66.4 \%$ ), whereas $K$. pneumoniae was resistant in $42 \%$ of isolates. This finding is much lower than that observed by Moolchandani et al. in $2017^{32}$.

Pseudomonas aeruginosa was resistant to carbapenem in $22 \%$ of isolates and was highly resistant to ceftazidime (in $81 \%$ of isolates) followed by gentamicin (57.5\%), ciprofloxacin $(22.5 \%)$ and amikacin $(9.5 \%)$. resistance to many antibiotic among $P$. aeruginosa was reported in many studies ${ }^{4,34}$.

The high level of resistance in the current study can be attributed to the unrestricted use of antibiotics in Sudanese hospitals; this injudicious use has been shown to have, an important role in increasing carbapenem resistance ${ }^{32}$. During this study, 134 gram negative bacilli resistant to three or four classes of antibiotics were isolated over a period of six months, which is relatively higher rate than the rate reported in a previous study also conducted in SUH over 30 months, from January 2011 to June $2013^{33}$. This concerning finding indicates the rapid acceleration in the rate of emergence of MDR organisms in our local sittings. Moreover, 80 bacterial strains were resistant to all available antibiotics, including meropenem.

In addition, microbiology laboratories play a crucial role against the spread of antimicrobial resistance by accurately identifying causative pathogens and detecting their antimicrobial susceptibility profile, so as to guide the proper use of antibiotics by the care providers. Unfortunately, in Sudan the lack of reliable 
microbiology laboratory services adds yet another layer to the multifactorial problem of MDR organisms' epidemic in our country. Most of the laboratories in our country use the disk diffusion method for antimicrobial susceptibility testing; however, there are no policies regarding phenotypic screening for antibiotic resistance among certain organisms; resulting in that the laboratory report may not be accurate and misguide the doctors. For instance, in the disk diffusion method, if the inhibitory zone around ceftazidime was $\leq 22 \mathrm{~mm}$, ideally this should trigger testing for the presence of ESBLs in the isolated pathogen, because the presence of these enzymes renders all penicillins, cephalosporins and monobactams ${ }^{12}$ useless against that certain isolate, even if they shows susceptible results in the routine test. Yet, this extra step is not taken and only the routine susceptibility results will be reported, which may inaccurately show some antibiotics as susceptible while in reality the organism is resistant to them. Lastly, there is a limited choice of available antibiotics in Sudan; the most widely available are cephalosporins, which makes them the backbone of treating infectious diseases regardless of the isolate or its susceptibility profile. Carbapenems are believed to treat all evils, once they were reserved for the treatment of MDR organisms causing systemic infections ${ }^{4}$, but the recent trend led to over use them for treating infections that can be managed by less potent antibiotics, contributing to this vicious cycle that aggravate the AMR issue even more.

\section{Conclusion}

In conclusion, there was a high prevalence of gram negative bacterial pathogen associated hospital and community acquired infections, with increasing rates of resistance to available antibiotics. Strict infection control measures should be implemented, and antimicrobial stewardship should be initiated and policed to decrease the spread of MDR pathogens in Sudanese hospitals.

\section{Data availability}

Raw data for the present study, including the genotypes, isolation location and resistance status of each bacterial isolate, is available of figshare. DOI: https://doi.org/10.6084/m9. figshare. $7584449^{35}$.

Data are available under the terms of the Creative Commons Attribution 4.0 International license (CC-BY 4.0).

\section{Grant information}

This research received partial research fund from the Ministry of Higher Education and Scientific Research, Sudan (grant number SUD/MOH/MMAH/08/2016).

The funders had no role in study design, data collection and analysis, decision to publish, or preparation of the manuscript.

\section{Acknowledgments}

We would like to thank the technical staff of Medical Microbiology Department in Soba University Hospital, University of Khartoum for their help in strain and data collection.

An earlier version of this article can be found on bioRxiv (DOI: https://doi.org/10.1101/486274).
1. Harris $\mathrm{P}$, Paterson $\mathrm{D}$, Rogers $\mathrm{B}$ : Facing the challenge of multidrug-resistant gram-negative bacilli in Australia. Med J Aust. 2015; 202(5): 243-7. PubMed Abstract | Publisher Full Text

2. Mehrad B, Clark NM, Zhanel GG, et al.: Antimicrobial resistance in hospitalacquired gram-negative bacterial infections. Chest. 2015; 147(5): 1413-21. PubMed Abstract | Publisher Full Text | Free Full Text

3. Masgala A, Kostaki K II: Multi Drug Resistant Gram Negative Pathogens in Long Term Care Facilities: A Steadily Arising Problem. J Infect Dis Diagn. 2015; 1(1): 101.

Publisher Full Text

4. Karaiskos I, Giamarellou H: Multidrug-resistant and extensively drug-resistant Gram-negative pathogens: current and emerging therapeutic approaches. Expert Opin Pharmacother. 2014; 15(10): 1351-70. PubMed Abstract | Publisher Full Text | Free Full Text

5. Rosenthal VD, Maki DG, Mehta Y, et al.: International Nosocomial Infection Control Consortium (INICC) report, data summary of $\mathbf{4 3}$ countries for 2007 2012. Device-associated module. Am J Infect Control. 2014; 42(9): 942-56. PubMed Abstract | Publisher Full Text

6. Huang TD, Bogaerts $\mathrm{P}$, Berhin $\mathrm{C}$, et al:: Increasing proportion of carbapenemase-producing Enterobacteriaceae and emergence of a MCR-1 producer through a multicentric study among hospital-based and private laboratories in Belgium from September to November 2015. Euro Surveill. 2017; 22(19): pii: 30530.

PubMed Abstract | Publisher Full Text | Free Full Text

7. Report G: Antimicrobial resistance. 2014

8. Wauters G, Vaneechoutte M: Approaches to the Identification of Aerobic GramNegative Bacteria. In: Manual of Clinical Microbiology. 11th ed. Washington, DC; 2015; 613-34. Publisher Full Text

9. Alsadig G, Arbab MA, Aldeaf SAH, et al:: Allele Frequency Of P53 Gene Arg72Pro
In Sudanese Meningioma Patients And Controls. InJ Sci Technol RES. 2014; 3(6): 2277-8616.

Reference Source

10. Srinivasan R, Karaoz U, Volegova M, et al:: Use of 16S rRNA gene for identification of a broad range of clinically relevant bacterial pathogens. PLOS One. 2015; 10(2): e0117617.

PubMed Abstract | Publisher Full Text | Free Full Text

11. Atschul SF, Madden TL, Schäffer AA, et al.: Gapped BLAST and PSI-BLAST: a new generation of protein database search programs. Nucleic Acid Res. 1997; 25(17): 3389-3402.

PubMed Abstract | Publisher Full Text | Free Full Text

12. Testing S: M100 Performance Standards for Antimicrobial. 27th ed. 2017; 106143.

Reference Source

13. Liu Y, Liu C, Zheng W, et al: PCR detection of Klebsiella pneumoniae in infant formula based on 16S-23S internal transcribed spacer. Int J Food Microbiol. 2008; 125(3): 230-5.

PubMed Abstract | Publisher Full Text

14. Sabat G, Rose P, Hickey WJ, et al:: Selective and sensitive method for PCR amplification of Escherichia coli 16S rRNA genes in soil. Appl Environ Microbiol. 2000; 66(2): 844-9.

PubMed Abstract | Publisher Full Text | Free Full Text

15. Spilker $\mathrm{T}$, Coenye $\mathrm{T}$, Vandamme $\mathrm{P}$, et al:: PCR-based assay for differentiation of Pseudomonas aeruginosa from other Pseudomonas species recovered from cystic fibrosis patients. J Clin Microbiol. 2004; 42(5): 2074-9. PubMed Abstract | Publisher Full Text | Free Full Text

16. Higgins PG, Wisplinghoff $\mathrm{H}$, Krut $\mathrm{O}$, et al: A PCR-based method to differentiate between Acinetobacter baumannii and Acinetobacter genomic species 13TU. Clin Microbiol Infect. 2007; 13(12): 1199-1201. PubMed Abstract | Publisher Full Text 
17. Zilberberg MD, Nathanson BH, Sulham K, et al.: Multidrug resistance, inappropriate empiric therapy, and hospital mortality in Acinetobacte baumannii pneumonia and sepsis Crit Care. 2016; 20(1): 221 PubMed Abstract | Publisher Full Text | Free Full Text

18. Yousif M: The prevalence of Extended Spectrum $\beta$-lactamase and AmpCProducing Bacteria in a Sudanese Tertiary Hospital. Sudan Med J. 2015; 5(3) Reference Source

19. Ibrahim ME, Bilal NE, Hamid ME: Comparison of phenotypic characteristics and antimicrobial resistance patterns of clinical Escherichia coli collected from two unrelated geographical areas. Glob J Heal Sci. 2014; 6(6): 126-35. PubMed Abstract | Publisher Full Text | Free Full Text

20. Cao X, Xu X, Zhang Z, et al:: Molecular characterization of clinical multidrugresistant Klebsiella pneumoniae isolates. Ann Clin Microbiol Antimicrob. 2014; 13: 16. PubMed Abstract | Publisher Full Text | Free Full Text

21. Meatherall BL, Gregson D, Ross T, et al:: Incidence, risk factors, and outcomes of Klebsiella pneumoniae bacteremia. Am J Med. 2009; 122(9): 866-873. PubMed Abstract | Publisher Full Text

22. Ali MA: the prevalence and characterization of antibiotic resistance among Gram-negative bacilli. University of Khartoum; 2013.

23. Karlowsky JA, Jones ME, Thornsberry C, et al.: Prevalence of antimicrobial resistance among urinary tract pathogens isolated from female outpatients across the US in 1999. Int J Antimicrob Agents. 2001; 18(2): 121-7. PubMed Abstract | Publisher Full Text

24. De Francesco MA, Ravizzola G, Peroni L, et al:: Urinary tract infections in Brescia, Italy: etiology of uropathogens and antimicrobial resistance of common uropathogens. Med Sci Monit. 2007; 13(6): BR136-44. PubMed Abstract

25. Blomberg B, Olsen BE, Hinderaker SG, et al:: Antimicrobial resistance in urinary bacterial isolates from pregnant women in rural Tanzania: implications for public health. Scand J Infect Dis. 2005; 37(4): 262-8. PubMed Abstract | Publisher Full Text

26. Haider G, Zehra N, Munir AA, et al.: Risk factors of urinary tract infection in pregnancy. J Pak Med Assoc. 2010; 60(3): 213-6. PubMed Abstract

27. Vincent JL, Rello J, Marshall J, et al.: International study of the prevalence and outcomes of infection in intensive care units. JAMA. 2009; 302(21): 2323-9. PubMed Abstract | Publisher Full Text

28. Javeri JR, Patel SM, Nayak SN, et al.: A study on bacteriological profile and drug sensitivity \& resistance pattern of isolates of the patients admitted in intensive care units of a tertiary care hospital in Ahmadabad. Natl J Med Res. 2016; 2(3): 330-4 Reference Source

29. Zavascki AP, Carvalhaes CG, Picã RC, et al:: Multidrug-resistant Pseudomonas aeruginosa and Acinetobacter baumannii: resistance mechanisms and implications for therapy. Expart Rev Anti infet ther. 2010; 8(1): 71-93. PubMed Abstract | Publisher Full Text

30. Lee S, Han SW, Kim KW, et al.: Third-generation cephalosporin resistance of community-onset Escherichia coli and Klebsiella pneumoniae bacteremia in secondary hospital. Korean J Intern Med. 2014; 29(1): 49-56. PubMed Abstract | Publisher Full Text | Free Full Text

31. Diene SM, Rolain JM: Carbapenemase genes and genetic platforms in Gramnegative bacilli: Enterobacteriaceae, Pseudomonas and Acinetobacter species. Clin Microbiol Infect. 2014; 20(9): 831-8. PubMed Abstract | Publisher Full Text

32. Moolchandani K, Sastry AS, Deepashree R, et al: Antimicrobial Resistance Surveillance among Intensive Care Units of a Tertiary Care Hospital in Southern India. J Clin Diagn Res. 2017; 11(2): DC01-DC07. PubMed Abstract | Publisher Full Text | Free Full Text

33. Elhag KM: Review Article Diversification of antibiotics as a means to control antimicrobial resistance and improve treatment options in Sudan. Sudan Med $J$. 2013; 49(3): 128-35 Reference Source

34. Magiorakos AP, Srinivasan A, Carey RB, et al:: Multidrug-resistant, extensively drug-resistant and pandrug-resistant bacteria: an international expert proposal for interim standard definitions for acquired resistance. Clin Microbiol Infect. 2012; 18(3): 268-81.

PubMed Abstract | Publisher Full Text

35. Elbadawi $\mathrm{H}$, Hamid MMA: Antimicrobial resistance surveillance among gram negative bacterial isolates from patients in hospitals in Khartoum State, Sudan .xIsx. figshare. Dataset. 2019. http://www.doi.org/10.6084/m9.figshare.7584449.v1 


\section{Open Peer Review}

\section{Current Peer Review Status: ? ? ?}

\section{Version 1}

Reviewer Report 17 June 2021

https://doi.org/10.5256/f1000research.19402.r86820

(C) 2021 Melano R. This is an open access peer review report distributed under the terms of the Creative Commons Attribution License, which permits unrestricted use, distribution, and reproduction in any medium, provided the original work is properly cited.

\section{Roberto G Melano}

Public Health Ontario Laboratory, University of Toronto, Toronto, Ontario, Canada

In Methods, I suggest this modification for the very long (and unclear) sentence:

"Guanidine chloride method, as described by Alsadig et al. ${ }^{9}$, was used for DNA extraction followed by PCR. Species-specific primers (Macrogen, Korea) were used for identification of Klebsiella pneumoniae, Escherichia coli, Pseudomonas aeruginosa, Acinetobacter baumannii; universal 16S rRNA primers were also used for identification of other species (Table 1). Each amplification was carried out in a total reaction volume of $25 \mu$ l: $5 \mu$ l Master mix of Maxime RT premix kit (iNtRON Biotechnology, Seongnam, Korea), $0.6 \mu$ l of forward primer, $0.6 \mu$ l of reverse primer, $2 \mu$ l of DNA and $16.8 \mu$ l deionized sterile water). The cycle condition were the following...".

In "Antimicrobial susceptibility testing" and Fig. 1, please check the spelling of some antibiotics (e.g. amoxicillin instead of amoxicillin, etc). In Fig. 1, 'augmentin' is a brand name. Please, use the generic name of the drug (amoxicillin clavulanate).

In "Classification of MDR gram-negative Bacilli", the definitions of MDR are not in reference 3, as mentioned by the authors. Please, add the correct reference, Magiorakos et al., (2012) ${ }^{1}$.

In the sentence 'Cephalosporin resistance was defined as resistance to ceftriaxone and ceftazidime, ...', it is interesting to see that the authors did not use the optional "or" instead of "and", since resistance to these antibiotics (cephalosporins and carbapenems) can be consequence of the presence of different mechanisms. For example, Enterobacteriaceae can be resistant to ceftazidime due to the presence of ESBLs such as PER-2 or from the SHV-family, but susceptible to ceftriaxone. Same for carbapenems (e.g. deficiency of the outer membrane protein OprD confers $P$. aeruginosa resistance to imipenem) and aminoglycosides (different aminoglycoside modifying enzymes can confer resistance to only gentamicin or amikacin). I suggest changing these criteria, and as consequence revise the number of isolates included in this study.

In Results, "Bacterial identification", I suggest changing 'strain' by 'species' in the sentence, "Isolated Gram-negative bacilli showed different strains, including...". 
The description in the second paragraph ('While isolates were distributed...') is not clear. I suggest deleting all this paragraph since Table 2 describes the same and in a very clear way. I just would keep the last 2 sentences ("K. pneumoniae was the most isolated organism from all hospital units. The distribution of different gram-negative isolates is shown in Table 2"). Please, use the abbreviated form of the bacterial names after these were mentioned (i.e. first mention: Klebsiella pneumoniae, after that, K. pneumoniae; same for all the species included in this manuscript).

It is not clear the meaning of the p-values in the Tables 2 and 3. Please, clarify.

In "Antimicrobial resistance pattern of clinical isolates", Fig. 1, I don't think the authors can present accumulative results for bacterial groups that were not tested by the same antibiotics (as showed in Figure 2). I'd delete Figure 1 and the first paragraph of this section.

In "Multidrug resistance patterns among gram negative Bacilli", why were only 600 isolates were analyzed? Why were the other 134 isolates not included in this analysis? I suggest adding a sentence explaining this issue. The \% of MDR (22.3\%) would be an underestimation considering my comment \#4 about the criteria for defining MDR.

In Discussion, in the paragraph starting in "Resistance of gram-negative bacilli is widespread and...", the authors didn't study the mechanisms of resistance but the susceptibility of the isolates. Then they can't talk about high rates of ESBLs. Maybe they wanted to say "resistance to extendedspectrum cephalosporins" ("resistance to ESBLs" is wrong). If that is the case, the authors have to change the sentence. I suggest: "In this study, we observed high rates of resistance to extendedspectrum cephalosporins (ceftazidime and ceftriaxone), in addition to resistance to cephalexin, cefuroxime, ampicillin and amoxicillin/clavulanic acid." If there are previous studies from Sudan, and/or close countries, about AMR, it would be interesting a paragraph comparing those results with the ones obtained in this manuscript. That would show the evolution of resistance in the country/region. Please, discuss some of these data in the manuscript.

\section{References}

1. Magiorakos AP, Srinivasan A, Carey RB, Carmeli Y, et al.: Multidrug-resistant, extensively drugresistant and pandrug-resistant bacteria: an international expert proposal for interim standard definitions for acquired resistance.Clin Microbiol Infect. 2012; 18 (3): 268-81 PubMed Abstract I Publisher Full Text

Is the work clearly and accurately presented and does it cite the current literature? Yes

Is the study design appropriate and is the work technically sound? Yes

Are sufficient details of methods and analysis provided to allow replication by others? Yes

If applicable, is the statistical analysis and its interpretation appropriate? Partly 
Are all the source data underlying the results available to ensure full reproducibility? No source data required

Are the conclusions drawn adequately supported by the results?

Partly

Competing Interests: No competing interests were disclosed.

Reviewer Expertise: Antimicrobial resistance

I confirm that I have read this submission and believe that I have an appropriate level of expertise to confirm that it is of an acceptable scientific standard, however I have significant reservations, as outlined above.

Reviewer Report 14 June 2021

https://doi.org/10.5256/f1000research.19402.r86818

(C) 2021 Rafei R. This is an open access peer review report distributed under the terms of the Creative Commons Attribution License, which permits unrestricted use, distribution, and reproduction in any medium, provided the original work is properly cited.

\section{Rayane Rafei}

Laboratoire Microbiologie Santé et Environnement (LMSE), Doctoral School of Science \& Technology, Faculty of Public Health, Lebanese University, Tripoli, Lebanon

This manuscript presents the surveillance data of antimicrobial resistance patterns of Gramnegative bacteria from patients in Khartoum State, Sudan. Such data are highly valuable from underrepresented regions. Nevertheless, this manuscript contains several flaws that must be addressed before acceptance.

\section{Comments:}

1. Is there a systematic collection of all Gram-negative bacteria isolated in the 8 hospitals mentioned in the materials and methods section? The authors should describe and clarify more their study design. The patients from whom bacteria were isolated are only inpatients admitted to hospitals or also including outpatients? These 8 hospitals are sole hospitals in the Khartoum state, are they representative of such state? It would be interesting to include more data on these hospitals.

2. The MDR definition adopted in the manuscript to categorize the strains as MDR is not wellreferenced. Usually, an isolate could be considered resistant to a group of antibiotics if it is resistant to at least one $(\geq 1)$ antibiotic agent in the group, not necessarily to all agents in the group (as mentioned in the second paragraph of the Classification of MDR Gram negative Bacilli). I recommend the authors to revaluate their data based on a good definition as that described in the reference Magiorakos et al. (2012)1. 
3. Reference 3 used for the definition of MDR in the introduction (and perhaps in the materials and methods) does not define such terms. Please verify that cited references matched well the text throughout the manuscript (as for reference 29 wherein the reference did not match the text).

4. Table 1, describing the bacterial gene primers used for PCR, must include a column for gene targets. In addition, it also contains many ambiguities to clarify:

The primers used for Acinetobacter identification are wrongly mentioned. Indeed, the sp4F and sp4R can identify both Acinetobacter genomic species 13TU (which is recently known as Acinetobacter nosocomialis) and $A$. baumannii. The primers Sp2F and sp4R can identify $A$. baumannii. A PCR with the 3 primers (sp2F, 4F, 4R) yields 2 bands when the isolate is $A$. baumannii (one $294 \mathrm{bp}$ with primer sp4F and sp4R and one $490 \mathrm{bp}$ with sp2F and sp4R), and only one band (294 bp with sp4F and sp4R) when the isolate is A. nosocomialis.

For the universal 16S rRNA, the reverse primer is not present in the mentioned reference (table 1).

Please, also use the bona fide name for primers as they are named in their original article (for example instead of $\mathrm{F}$ use the 27F (5'-AGAGTTTGATCCTGGCTCAG-3')).

5. The statistical analysis paragraph should be reformulated. Moreover, what statistical relationships do the authors use to reveal by the mentioned P-values in tables 2 and 3 ?

6. Was the 16S rRNA gene sequencing carried out to all Gram-negative bacteria isolates, even those identified using PCR with species-specific primers?

7. Which cut-off has been used for the identification of species when blasting the 16S rDNA sequence, what is the NCBI database that has been used (nucleotide collection $\mathrm{nr} / \mathrm{nt}$ or rRNA/ITS database)?

8. Please verify the charge of antibiotic disks as the charge of trimethoprim-sulfamethoxazole (SXT) should be 1.25/23.75 $\mu \mathrm{g}$.

9. Why are the antibiotics ticarcillin, ticarcillin-clavulanate, piperacillin, piperacillin-tazobactam and cefepime not tested?

10. Why include only 600 GNB for studying the MDR, however, the authors start with 743 isolates. The reasons should be clearly stated in the text.

11. Why are the data on drug susceptibility about Stenotrophomonas maltophilia and Burkholderia cepacia and other bacteria (as Enterobacter) not mentioned in the results section and analyzed in the discussion. What are the definitions used to define MDR in these bacterial isolates?

12. The authors define the distribution of species according to the hospital wards and specimens. However, data concerning the distribution of species according to studied hospitals is also interesting.

13. Amikacin and imipenem have a low percentage of resistance, why was amikacin not listed as the most effective antibiotic along with imipenem (paragraph one - antimicrobial resistance 
pattern of clinical isolates).

14. In the discussion, the authors refer the increase of resistance in their hospitals to the unrestricted use of antibiotics in Sudanese hospitals. However, the misuse of antibiotics in the community and extra-hospital settings can also affect this upward trend. Addressing the one health concept is a way to cope with the rising threat of antimicrobial resistance. In addition, this increase in antimicrobial resistance in Sudanese hospitals may due to the occurrence of (silent) outbreaks that need investigation and control.

15. Could the author explain what did they mean in the discussion by: "In this study, we observed high rates of resistance to extended-spectrum B-lactamases (ESBL)".

16. In the discussion, the authors concluded that the resistance rate (134 gram-negative bacilli resistant to three or four classes of antibiotics isolated over a period of 6 months) is relatively higher than the rate reported in a previous study also conducted in SUH over 30 months from January 2011 to June 2013 (reference 33). The authors of reference 33 isolated 80 bacterial strains resistant to all available antibiotics including meropenem (Microbiology records SUH). Did the authors of the manuscript isolate the same number of isolates that are resistant to all available antibiotics including meropenem as stated in the last sentence, "This concerning finding...Including meropenem")?

17. The authors must compare their findings in the discussion to those obtained in the MENA and the surrounding region. Following are some reviews addressing resistance in such regions: AlOrphaly et al. (2021) ${ }^{2}$, Moghnieh et al. (2018) ${ }^{3}$, and Dandachi et al. $2019^{4}$.

18. The authors should be aware when formulating their findings: is actually $K$. pneumoniae the most commonly isolated organism from the blood specimens among all organisms? Or within Gram-negative bacteria? The same applies to other findings? And if among all organisms, these data are not represented in the text. Please revise the text accordingly.

19. The language is generally good in the text, however, many paragraphs and sentences are written poorly. For example:

"by using the following primers (Macrogen, Korea), using species-specific primers";

"The purity and integrity of each PCR product was evaluated electrophoresis in a $2 \%$ agarose gel";

There are also many typos in the text as (use Aztreonam instead of aztreoname, settings instead of sittings, Enterobacter cloacae instead of Enterobacter colecaes) and in Figure 1 (cotrimoxazole instead of cotramoxazole, even I prefer using the same nomenclature for antibiotics in the text as well as in the figure).

These aforementioned examples are not exhaustive; therefore, the text should be revised accordingly, and I suggest a language edit.

20. Verify numbers in the text, table, and figure throughout the text. For instance, how did the authors get the number 86 isolates that are resistant to three classes of antimicrobial drugs, as well as for the $38 \mathrm{~A}$. baumannii isolates that are also resistant to three classes of antimicrobial drugs? These numbers did not match table 4 . Another example is the percentage of ceftazidime- 
resistant E. coli: in the text $84.2 \%$ vs in the figure $280.60 \%$.

21. Table 4 should be reorganized to become more visible and clearer. Simply, the authors can drop the last row (total row) because it confuses the readers about what the total row is standing for.

22. In the text, when mentioning authors of a reference in the discussion, please write the last name of the first author (not the first name) of the citation as mentioned in the reference list. Instead of Jitendra et al., (discussion) please mention Javeri et al., as reference 28 in the reference list. Gales et al., 2010 is used to refer to reference 29, while it should be mentioned as Zavascki et al., 2010.

23. Please capitalize the first letter in the word (gram) throughout the text.

24. Once the full name of bacteria species is defined for the first time (ex: Klebsiella pneumoniae), use the abbreviated form (K. pneumoniae) throughout the text. The same applies to other abbreviated forms as Intensive care units, one ICU is spelled out for the first time mentioning intensive care units in the text, use the abbreviated form throughout the text.

\section{References}

1. Magiorakos AP, Srinivasan A, Carey RB, Carmeli Y, et al.: Multidrug-resistant, extensively drugresistant and pandrug-resistant bacteria: an international expert proposal for interim standard definitions for acquired resistance.Clin Microbiol Infect. 2012; 18 (3): 268-81 PubMed Abstract | Publisher Full Text

2. Al-Orphaly M, Hadi HA, Eltayeb FK, Al-Hail H, et al.: Epidemiology of Multidrug-Resistant Pseudomonas aeruginosa in the Middle East and North Africa Region.mSphere. 2021; 6 (3). PubMed Abstract | Publisher Full Text

3. Moghnieh R, Kanafani Z, Tabaja H, Sharara S, et al.: Epidemiology of common resistant bacterial pathogens in the countries of the Arab League. The Lancet Infectious Diseases. 2018; 18 (12): e379e394 Publisher Full Text

4. Dandachi I, Chaddad A, Hanna J, Matta J, et al.: Understanding the Epidemiology of Multi-Drug Resistant Gram-Negative Bacilli in the Middle East Using a One Health Approach.Front Microbiol. 2019; 10: 1941 PubMed Abstract | Publisher Full Text

Is the work clearly and accurately presented and does it cite the current literature? Yes

Is the study design appropriate and is the work technically sound? Yes

Are sufficient details of methods and analysis provided to allow replication by others? Yes

If applicable, is the statistical analysis and its interpretation appropriate? Partly

Are all the source data underlying the results available to ensure full reproducibility? 


\section{No source data required}

Are the conclusions drawn adequately supported by the results?

Yes

Competing Interests: No competing interests were disclosed.

Reviewer Expertise: Molecular epidemiology of infectious diseases

I confirm that I have read this submission and believe that I have an appropriate level of expertise to confirm that it is of an acceptable scientific standard, however I have significant reservations, as outlined above.

Reviewer Report 04 May 2021

\section{https://doi.org/10.5256/f1000research.19402.r84294}

(C) 2021 Markwart R. This is an open access peer review report distributed under the terms of the Creative Commons Attribution License, which permits unrestricted use, distribution, and reproduction in any medium, provided the original work is properly cited.

\section{Robby Markwart}

${ }^{1}$ Infectious Disease Epidemiology, Robert Koch Institute, Jena University Hospital, Nordufer, Berlin, 13353, Germany

2 Jena University Hospital, Institute of General Practice and Family Medicine, Jena, Germany

The study Antimicrobial resistance surveillance among gram-negative bacterial isolates from patients in hospitals in Khartoum State, Sudan by Hana Salaheldin Elbadawi et al. investigates the spectrum of gram-negative bacterial pathogens and antimicrobial resistance patterns in Khartoum State, Sudan.

The manuscript is generally well written and the data are presented in a clear way. However, I have some suggestions, which may help to improve the manuscript.

Specific comments:

The authors state that isolates from eight hospitals in Khartoum state were included in the study. Include these eight hospitals all hospitals in Khartoum State or are they are a sample of more hospitals?

The study was carried out between October 2016 and February 2017, i.e. encompassing the winter season. Is it possible that the spectrum of gram-negative pathogens could be different in the summer season?

In table 2 and 3, what exactly do the p-values indicate? What is the purpose of the p values? If the authors want analyze whether there are statistical differences in the proportion of isolates between in hospital wards (Table 2 ) or clinical sample materials (Table 3), I also 
suggest adding $95 \%$ confidence intervals of the proportions.

I personally do not like the visual style of the Figures (Figures 1 and 2). From my knowledge, 3-dimensional bar charts are unusual in scientific publications. I suggest designing the figures in a more scientific format. Moreover, I suggest adding figure legends that include the total number of isolates tested per antibiotic. Furthermore, the authors could consider adding 95\% confidence intervals to the bar charts since the study represents a more or less random sample of isolates in Sudan. The authors should discuss the representativeness of their study for Sudan or even North-East Africa.

In the discussion, the authors conclude that " $K$. pneumonia was the most commonly isolated organism from the blood specimens mainly in neonatal sepsis in a high rate (39.8\%)." This might be correct, but the study only analyzes the distribution of gram-negative pathogens. That means from the data presented in the manuscript, the authors only can conclude that $\mathrm{K}$. pneumonia is the most frequent pathogen among gram-negative pathogens. Similarly, the authors state that the most frequently observed pathogens in urine specimens were E. coli and K. pneumonia. Again, this only true among gram-negative pathogens. At least in Germany, gram-positive Enterococcus spp. are the second most frequent found pathogens in urine samples (Klingeberg 2018).

In the discussion, it would be helpful to compare the resistance patterns with studies from the same region in Sudan or surrounding regions / countries. Are the resistance proportions higher or lower in Khartoum State compared to surrounding regions / countries? Similarly, the authors could compare their resistance patterns with other regions of the world. For Europe, I suggest data from EARS-Net (European Antimicrobial Resistance Surveillance Network), for the United States CDC data are available. For example, in Germany, a nationwide study showed that only $3.5 \%$ of all A. baumannii (complex) isolates were carbapenem resistant (Said et al. Antimicrob Resist Infect Control 2021 Mar 1;10(1):45 ). For China, there are multiple systematic reviews and meta-analyses for antimicrobial resistance proportions for different pathogens available. A systematic comparison of the resistance rates described in this study with resistance patterns in other regions would help to put the data in perspective.

In the introduction, the authors state "This study may help in formulating antibiotic policies tailored to our hospitals. These data can be used as information for action" antibiotic stewardship and interventions to optimize antibiotic prescribing practice, therefore prolongs the usefulness of existing antibiotics.". However, in the discussion these aspects are not addressed properly. What clinical conclusions do the authors draw from their data? How do these data help to taylor ABS interventions? Etc.

Minor comments:

- I suggest a profound proof reading in order to correct spelling mistakes and typos in the manuscript.

I suggest adding a column "Total" in Tables 2 and 3 to indicate the total numbers of the isolated pathogens (e.g. Table 2: 249 for K. pneumonia)

\section{References}


1. Said D, Willrich N, Ayobami O, Noll I, et al.: The epidemiology of carbapenem resistance in Acinetobacter baumannii complex in Germany (2014-2018): an analysis of data from the national Antimicrobial Resistance Surveillance system. Antimicrobial Resistance \& Infection Control. 2021; 10 (1). Publisher Full Text

Is the work clearly and accurately presented and does it cite the current literature? Yes

Is the study design appropriate and is the work technically sound?

Yes

Are sufficient details of methods and analysis provided to allow replication by others? Yes

If applicable, is the statistical analysis and its interpretation appropriate? Partly

Are all the source data underlying the results available to ensure full reproducibility? No source data required

Are the conclusions drawn adequately supported by the results? Yes

Competing Interests: No competing interests were disclosed.

Reviewer Expertise: infectious disease epidemiology

I confirm that I have read this submission and believe that I have an appropriate level of expertise to confirm that it is of an acceptable scientific standard, however I have significant reservations, as outlined above. 
The benefits of publishing with F1000Research:

- Your article is published within days, with no editorial bias

- You can publish traditional articles, null/negative results, case reports, data notes and more

- The peer review process is transparent and collaborative

- Your article is indexed in PubMed after passing peer review

- Dedicated customer support at every stage

For pre-submission enquiries, contact research@f1000.com 